\title{
Non-chondritic yttrium/holmium ratio and lanthanide tetrad effect observed in pre-Cenozoic limestones
}

\author{
Iwao KaWABe, YoKo KitahaRa and KoH NaIto \\ Department of Earth Sciences, Faculty of Science, \\ Ehime University, Bunkyo-cho 2-5, Matsuyama 790, Japan
}

(Received July 27, 1990; Accepted March 26, 1991)

\begin{abstract}
REE and Y in limestones have been determined by ICP-AES method coupled with pre-concentration chemical procedures. The lanthanide tetrad effect has been clearly observed in the REE patterns of two Permian limestones. It is the W-type tetrad effect seen in seawaters. Y/Ho ratios for the limestones show large positive deviations from the chondritic ratio. Similar non-chondritic $\mathrm{Y} / \mathrm{Ho}$ ratios are seen in a Precambrian limestone from South Africa, seawaters, and marine phosphorites. Their REE patterns are well characterized by the W-type tetrad effect. These facts and recent results of aquatic geochemistry of REE and Y strongly suggest that the positive $\mathrm{Y}$ anomalies are intimately associated with the W-type tetrad effect of REE in natural aquatic solutions including seawaters and in some hydrogenous deposits from the solutions. Y is not a pseudo lanthanide that behaves like Ho in natural conditions where the lanthanide tetrad effect is operative. This must be a thermochemical effect related to the absence of $4 \mathrm{f}$ electron in $\mathrm{Y}^{3+}$ and the systematic differences in $4 \mathrm{f}$ electronic configurations in the $\mathrm{REE}^{3+}$ series. The REE plus $\mathrm{Y}$ patterns with positive $\mathrm{Y}$ anomalies and the W-type tetrad effect are important for the geochemical studies of limestones and other hydrogeneous deposits.
\end{abstract}

\section{INTRODUCTION}

Masuda and Ikeuchi (1979) first demonstrated that the lanthanide tetrad effect in nature is recognized in peculiar REE abundance patterns for seawaters and a marine phosphate nodule. Subsequently, Masuda and his coworkers further found that such tetrad effects are detectable in other natural substance including limestones, valves of living shellfish, fresh groundwaters, siliceous ores, leucogranites and so on (Kamioka and Masuda, 1986; Masuda et al., 1987; Masuda and Akagi, 1989). On the other hand, detailed studies on REE distribution in Pacific and Atlantic ocean water columns made by De Baar et al. (1983 and 1985a, b) provide further evidence for the lanthanide tetrad effect in seawaters. Recently, Masuda et al. (1987) proposed to distinguish two types of tetrad effects in nature: The first one called the W-type by them is observed in natural waters and related materials. The other one called the M-type is observed in solid materials that are probably having remained after leaching by aqueous media. They emphasized the complementary relationship between the $\mathrm{W}$ and $\mathbf{M}$ tetrad effects.

The tetrad effect itself was proposed originally by Peppard et al. (1969 and 1970) on the basis of their studies on solvent extraction of trivalent lanthanides and actinides. According to their works, when the logarithmic distribution coefficients for trivalent REE between organic and aqueous phases are plotted against the atomic number of the lanthanide, the plot appears to consist of four distinct smooth curves. The fifteen REE are grouped by the curves into four tetrads with $\mathrm{Gd}$ being common to the second and third tetrads. The extended smooth curves for the first and second tetrads and those for the third and fourth tetrads intersect respectively between $\mathrm{Nd}$ and $\mathrm{Pm}$ and between Ho and 
Er. In a similar plot for trivalent actinides, they showed that an analogous tetrad effect is apparent with $\mathrm{Cm}$ being common to the second and third tetrads. They wrote that, if the lanthanide tetrad effect should be valid, the "half-filled" shell effect would be joined by the "one-quater-filled" shell effect and "threequaters-filled" shell effect because of the discontinuities occurring respectively between the third and fourth and between the tenth and eleventh $4 \mathrm{f}$ electron additions.

In response to the proposal of tetrad effect, Jørgensen (1970) and Nugent (1970) put forward quantum mechanical interpretations for the tetrad effects in terms of the interelectron repulsion energy of the $q$ electrons in each $4 f^{q}$ or $5 f^{q}$ electronic configuration for trivalent lanthanides and actinides.

If the lanthanide tetrad effect is related to the ground state electronic configurations in which the $4 \mathrm{f}$ sub-shell is successively filled by an additional electron, the relationship between Ho and $\mathrm{Y}$ is important because the trivalent ionic radii for $\mathrm{Ho}$ and $\mathrm{Y}$ are almost the same despite no $4 \mathrm{f}$ electron in Y. In this respect, Peppard et al. (1969) themselves noted that $Y$ does not always behave as a pseudo lanthanide in solvent extract ions for REE. The distribution coefficient for $Y$ in a solvent extraction system involving H[DOP] (benzene) and $\mathrm{HCl}$ (aqueous) is comparable with that for Ho or Er. However, in the other extraction system utilizing DEH[CIMP] (benzene) and $\mathrm{LiBr}$ plus $\mathrm{HBr}$ (aqueous), such a coefficient for $\mathrm{Y}$ differs greatly from any values of the coefficients for all the REE.

In this context, it is interesting and important to study the lanthanide tetrad effect and the fractionation between $\mathrm{Y}$ and Ho or other heavy REE together even in natural substance. However, almost all previous analytical results relevant to the tetrad effects in natural samples include neither $\mathrm{Y}$ data nor the information as to $\mathrm{Y} / \mathrm{Ho}$ fractionations, because the mass spectrometric isotope dilution method (MSID) has been used principally. In this paper, we report REE and Y determinations for some Japanese pre-Cenozoic limestones using the inductively coupled $\mathrm{Ar}$ plasma-atomic emission spectrometry (ICPAES) after the group separation of these elements from matrix major elements. The geochemical importance of intimate association of non-chondritic $\mathrm{Y} / \mathrm{Ho}$ ratios with the W-type lanthanide tetrad effect in limestones and seawaters is discussed.

\section{SAMPLES}

Two limestones (EL-1 and EL-2) were sampled from the Lower to Middle Permian limestone body in Ohnogahara, Nonura-cho, Ehime Prefecture. The limestone body occurs together with greenstones, cherts, and clastic rocks. They are collectively designated the Ohnogahara Group and one of the key pre-Cenozoic geological units that constitute the Northern Chichibu Belt in the western part of Shikoku Island, Japan. The other is a calcareous gneiss sampled in Nishisetodani area along Ohnagatani River, Yatsuo-cho, Nei-gun, Toyama Prefecture. This is a typical sample of the most calcareous member of the calc-silicate gneiss of the Hida metamorphic rocks. The calc-silicate gneiss is characterized as alternations of marbles and quartzites. This sample was taken from a marble-rich portion. It consists of calcite mainly, and accessory amounts of quartz, clinopyroxene, and tremolite are present. This sample differs petrographically from the two samples of the Ohnogahara limestone in having silicate impurities in it.

\section{EXPERIMENTAL}

The aliquots of each powdered sample weighing $10-30 \mathrm{~g}$ have been used for repeated analyses of three to six times, because the REE and $\mathrm{Y}$ contents were expected to be as low as chondrite levels. Two methods for sample decomposition were used in order to ensure the presence or absence of non-carbonate impurities that may have those elements and resist the chemical dissolution by mineral acids or by HF plus mineral acids. The first method is the dissolution by $\mathrm{HCl}$ alone. The solution is filtered 
to remove insoluble materials if present. Only the filtrate is used in subsequent procedures for the group separation of REE and Y. The other method includes additional decomposition procedures to make all the constituent materials soluble as completly as possible. The filtered insoluble materials after dissolution by $\mathrm{HCl}$ are ignited in a Pt-crucible, and then dissolved by $\mathrm{HF}+\mathrm{HNO}_{3}+\mathrm{HClO}_{4}$ twice. It is filtered again, and this filtrate is combined with the first filtrate after dissolution by $\mathrm{HCl}$. The filterd insolubles, after being ignited in a Pt-crucible again, are further fused with $300 \mathrm{mg}$ of $(2: 1)$ mixture of $\mathrm{Na}_{2} \mathrm{CO}_{3}$ and $\mathrm{H}_{3} \mathrm{BO}_{3}$. If necessary, this fusion is repeated twice. The fusion product is then dissolved in $\mathrm{HCl}$ and added to the combined solution of the first and second filtrates. This is the sample solution obtained by the second decomposition method.

Both of the sample solutions by the two digestion methods are used in the same procedures for group separation of REE and Y, in which coprecipitation with $\mathrm{Fe}(\mathrm{OH})_{3}$ is followed by the cation-exchange purification. The co-precipitation is made at $\mathrm{pH}=6.5$ by adding $20 \mathrm{mg} \mathrm{Fe}^{3+}$ and ammonia water. This is repeated for the filterate separated from the hydroxide precipitate in order to make the final recovery satisfactory. The first and second precipitates are combined and dissolved in $1.76 \mathrm{M} \mathrm{HCl}$ for the cation-exchange separation of REE and $\mathrm{Y}$ from $\mathrm{Fe}$ and other matrix elements. The columns $(1 \mathrm{~cm} \times 11$ $\mathrm{cm})$ of Dowex $50 \mathrm{~W} \times 8(200-400$ mesh) are used. $60 \mathrm{ml}$ of $1.76 \mathrm{M} \mathrm{HCl}$ is used to load the sample solution and to elute $\mathrm{Fe}^{3+}$ and other major cations. REE and Y are eluted by $120 \mathrm{ml}$ of $6 \mathrm{M}$ $\mathrm{HCl}$. After evaporation of the $\mathrm{HCl}$ solution containing REE and $\mathrm{Y}$ to dryness, it is dissolved in $50 \mathrm{ml}$ of $0.34 \mathrm{M} \mathrm{HCl}$ and then used to determine REE and $Y$ by ICP-AES.

The ICP emission spectrometer used in this study is a Shimazu ICPS-50. The operating conditions and parameters of the spectrometer have been described elswhere (Kawabe et al., 1988). Emission intensity data for all REE and Y together with $\mathrm{Ca}$ in the final sample solutions and standard solutions were acquired. The cor- rections for spectral interferences among the measured elements were made in calculating the final results of the concentrations of REE and Y in samples. The linear correction factors for spectral interferences among REE, $\mathrm{Y}$ and $\mathrm{Ca}$ have been re-determined for this study, and the previous set by Kawabe et al. (1988) was slightly revised. The blank tests for all the chemical procedures indicate that the blank correction is unnecessary.

As a result of REE and Y analyses in standard rocks and clastic rocks enriched in heavy minerals, we confirmed that the residues after the dissolution by HF-mineral acids can be completely dissolved by the fusion procedure using $\mathrm{Na}_{2} \mathrm{CO}_{3}$ and $\mathrm{H}_{3} \mathrm{BO}_{3}$ (Kawabe et al., in preparation). So that we believe that all materials in each sample are satisfactorily decomposed into the solution by the second method. By using the sample solution spiked with the standard solution having $100 \mu \mathrm{g}$ of $\mathrm{La}, \mathrm{Eu}, \mathrm{Lu}$ and $\mathrm{Y}$ each, the recovery in the group separation was checked. The recovery of more than $99 \%$ was found for each spiked element. The alkali earth elements and trivalent major elements are negligible in the final solution except for a minor amount of $\mathrm{Ca}$. The level of $\mathrm{Ca}$ concentrations ranges from 70 to $200 \mathrm{ppm}$, but it is not high enough to cause significant chemical interferences in the ICP emission spectrometry for REE and $\mathrm{Y}$.

\section{Results}

Each sample has been analyzed three times or more, in which the two methods for sample digestion described above were applied. No significant differences in REE and $\mathrm{Y}$ results between the two methods were found even in the case of the calcareous gneiss. So that the analytical results of all runs for each sample were averaged irrespective of the decomposition methods, and the mean values and one-sigma errors for the respective means were calculated. These are listed in Table 1 together with the number of repeated analyses. The data on the surface seawater and the $\mathrm{C} 1$ chondrite are also listed in Table 1, since these data are used to discuss the 


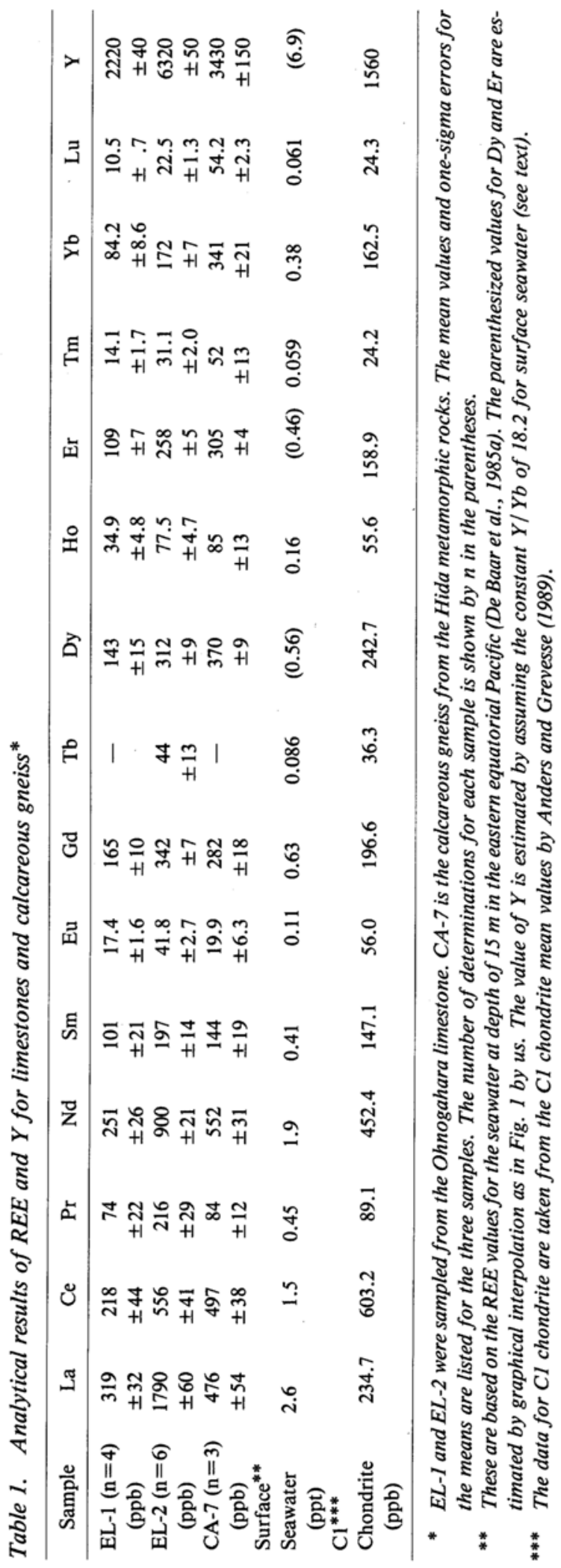

present results in the next section.

The REE data for the surface seawater are taken from De Baar et al. (1985a). This set of data is for the Pacific Ocean water at depth of $15 \mathrm{~m}$ from sea surface at the VERTEX II site. Because Dy, Er and Y were not measured by De Baar et al. (1985a), we estimated probable values for Dy and Er by interpolating in the REE abundance pattern (see Fig. 1). The Y value which could be consistent with the REE data by De Baar et al. (1985a) has been estimated by assuming a reasonable $\mathrm{Y} / \mathrm{Yb}$ ratio as follows: We have estimated the $\mathrm{Y} / \mathrm{Yb}$ ratio from the previous works that report not only REE concentrations in seawater samples but also the $\mathrm{Y}$ concentrations. Høgdahl et al. (1968) have reported such NAA data for seawater samples from the central Atlantic. Martin et al. (1976) have listed similar NAA determinations for an estuarine water with 28.3\% salinity in Gironde, France. Daidoji et al. (1985) have reported ICP-AES data of Y and some REE for the surface seawater $100 \mathrm{~m}$ off the Pacific coast at Kumomi on the southwestern corner of Izu Peninsula, central Japan. The REE data by De Baar et al. (1985a, b), Martin et al. (1976) and Daidoji et al. (1985) show abundance patterns for heavy REE almost parallel to each other. However, the heavy REE abundances in the Atlantic seawater samples by Høgdahl et al. (1968) are found to be slightly different from the above three. The Atlantic seawater samples have not been collected from the ocean surface but from various depths greater than $900 \mathrm{~m}$. Therefore, from the data by Martin et al. (1976) and Daidoji et al. (1985), we have estimated an $\mathrm{Y} / \mathrm{Yb}$ ratio of $18.2 \pm 0.6$ for the surface seawater. This gives the $\mathrm{Y}$ value of $6.9 \mathrm{ppt}$ listed in Table 1. We did not use the $\mathrm{Y} / \mathrm{Ho}$ ratio, because Ho analyses by NAA and ICP-AES are subjected to larger analytical errors than $\mathrm{Yb}$ analyses.

The REE and $\mathrm{Y}$ data for the $\mathrm{C} 1$ chondrite are taken from the table of the $\mathrm{Cl}$ chondrite mean values by Anders and Grevesse (1989). Their REE values for the $\mathrm{C} 1$ chondrite are strikingly parallel to the REE values for the ordinary condrite of Leedey (L6) by Masuda et al. (1973) and 


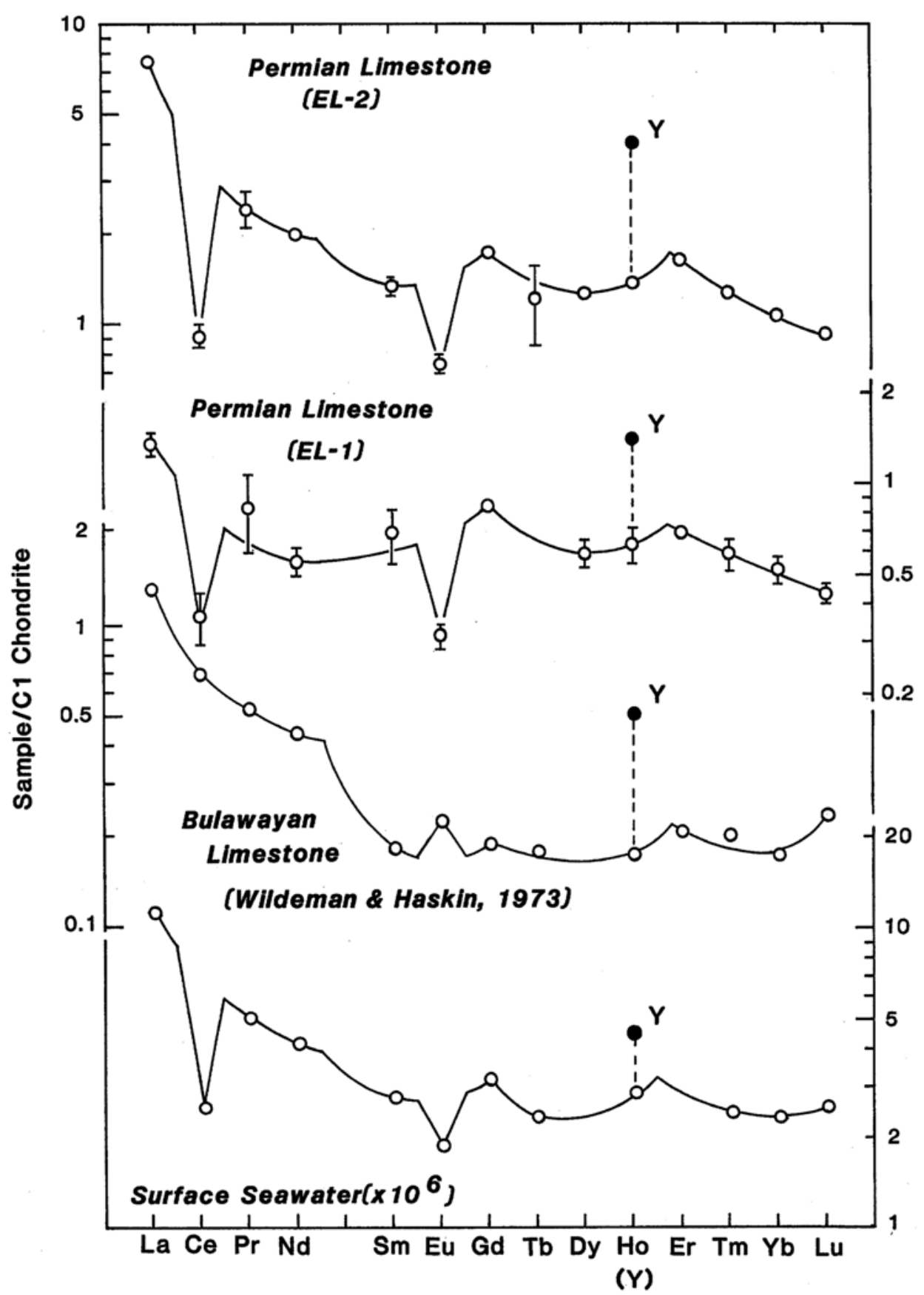

Fig. 1. REE plus Y abundance patterns for Permian and Precambrian limestone samples compared with the pattern for the surface seawater. The two Permian samples are from the Ohnogahara group (this study). The data for the Precambrian Bulawayan limestone are after Wildeman and Haskin (1973). The data and their sources on C1 chondrite for normalization and surface seawater are listed in Table 1. 
Masuda (1975) with a constant factor of $0.631 \pm 0.012$ for all REE. Either set of chondritic REE reference values for normalization, therefore, can give essentially the same REE abundance patterns. However, the set for the Leedey does not include the $\mathrm{Y}$ concentration. In order to discuss REE and Y together, we preferred the $\mathrm{Cl}$ chondrite mean values to the Leedey values.

\section{Discussion and Conclusions}

\section{Characteristics of REE plus Y Abundance Pat- terns}

The REE plus Y abundance patterns normalized by $\mathrm{C} 1$ chondrite for the three samples in this study are shown in Figs. 1 and 2, together with those for the surface seawater and the two Precambrian carbonate rocks reported by Wildeman and Haskin (1973). The two Permian limestone samples (EL-I and EL-2) show quite similar patterns commonly characterized by (1) the W-type tetrad effect, (2) large Y/Ho ratios with positive deviations from the chondritic value, and (3) negative anomalies of $\mathrm{Ce}$ and $\mathrm{Eu}$. Their abundance patterns for heavy REE are very alike each other, but a noticeable difference can be seen in light REE, especially, in the first tetrad. We like to emphasize that the three characteristics are also recognized in the REE plus $Y$ abandance pattern for the surface seawater. The pattern for the Precambrian Bulawayan limestone by Wildeman and Haskin (1973) indicates a similar large $\mathrm{Y} / \mathrm{Ho}$ ratio. The concave REE patterns for the first and second tetrads in the Precambrian Bulawayan limestone are diagnostics of the W-type tetrad effect, although no negative anomalies of $\mathrm{Ce}$ and $\mathrm{Eu}$ are observed.

The REE and Y pattern for the calcareous gneiss (CA-7) in Fig. 2 is quite different from all the patterns in Fig. 1. The tetrad effect in heavy REE is not obvious and the fractionation between $\mathrm{Y}$ and Ho or other heavy REE is moderate, despite that a slightly concave pattern is recognized for the first tetrad. The Red Creek marble by Wideman and Haskin (1973) cited in
Fig. 2 shows that the $\mathrm{Y} / \mathrm{Ho}$ ratio is very close to the chondritic one. The REE pattern for the marble is characterized by a straight line at least for the segment from La through Ho, suggesting that the lanthanide tetrad effect is probably absent. Haskin et al. (1966) have reported REE and Y data for nine carbonate samples including six limestones and two marbles. The REE plus Y abundance patterns for all their carbonates appear to resemble the pattern for the Red Creek marble. However, fine features of their patterns are not so clear, probably because the analytical uncertainties in their neutron activation analysis for these carbonates with low contents of REE and $\mathrm{Y}$ are considerable.

The close resemblance in REE and $Y$ abundance patterns between the limestones and the surface seawater in Fig. 1 is quite expectable, if the limestones have been formed in shallow marine environments. The Ohnogahara limestone body is thought to be the remains of a Permian coral reef formed on the summit of a seamount at that time like other similar preCenozoic limestone bodies in southwest Japan (Kanmera, 1987). This type of limestones does not intercalate any terrigenous materials and always occurs overlying upon greenstones or volcano-clastic rocks. These geological facts are consistent with the geochemical characteristics of the Ohnogahara limestone from REE and Y abundances. If significant amounts of terrigenous materials are present in limestones, their REE patterns become much similar to those of igneous rocks. The $\mathrm{Y} / \mathrm{Ho}$ ratios also become much close to the chondritic value as in igneous rocks. The source carbonate materials of the Red Creek marble, in this context, may have been formed under such an environment that some significant influx of terrigenous materials was present.

In view of the REE and Y patterns, the Hida calcareous gneiss does not seem to resemble either the Ohnogahara limestone as a coral reef limestone or the Red Creek marble as a representative carbonate rock having terrigenous materials. As noted earlier, the Hida calcareous gneiss and calc-silicate gneiss occur as alterna- 


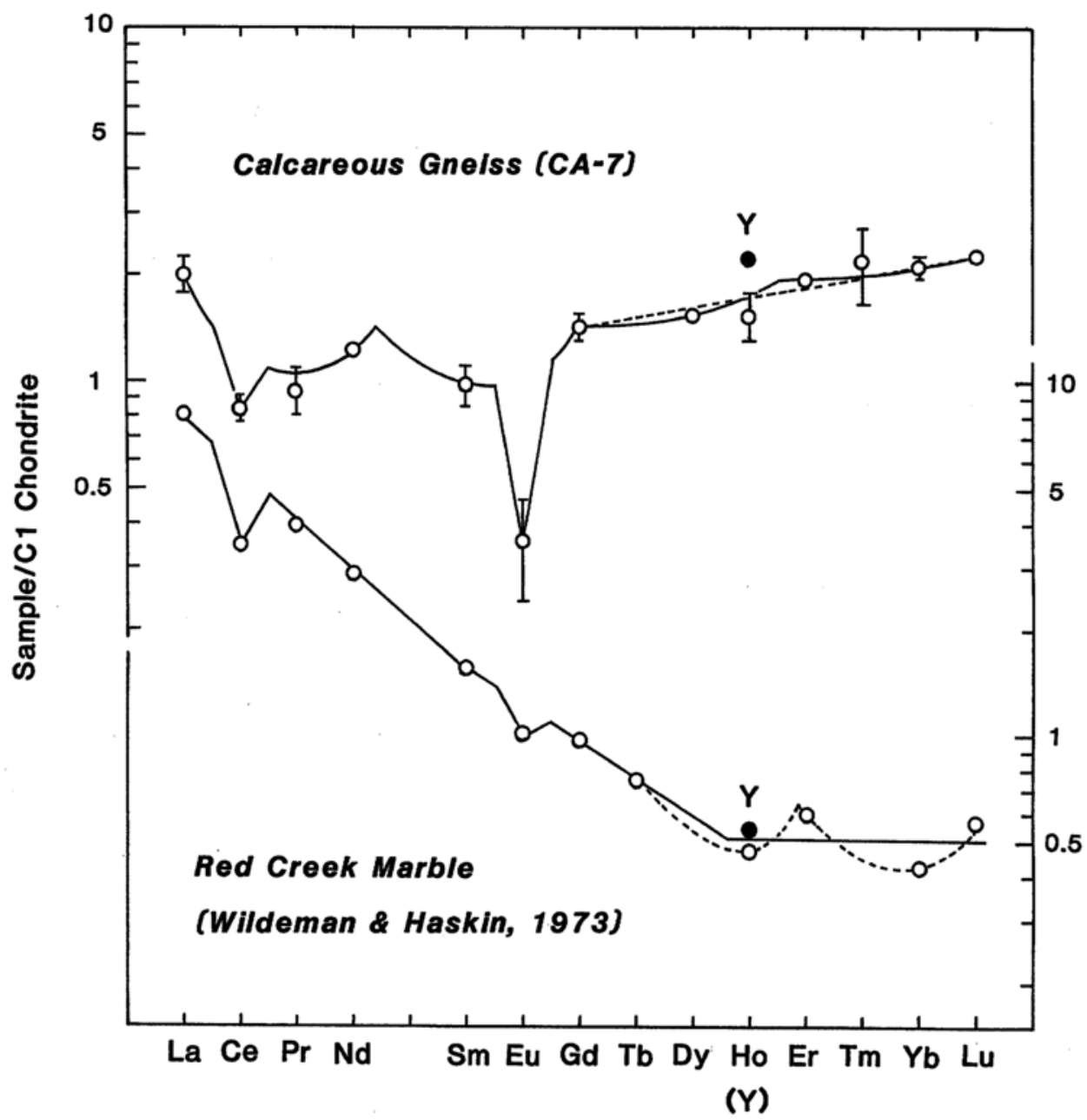

Fig. 2. REE plus Y abundance patterns for the Hida calcareous gneiss (this study) and for the Red Creek Marble (Wildeman and Haskin, 1973).

tions of marbles and quartzites. They are subjected to high-temperature type regional metamorphism of upper amphibolite facies to granulite facies. Such marbles usually contain small amounts of dolomite component up to 5 mole $\%$. These facts indicate that the calcareous source materials initially deposited along with quartz-rich detritus materials and then suffered from some weak dolomitization and regional metamorphism. However, it is difficult to determine whether the dolomitization occurred just after depositional stage or during the metamorphism. The detritus materials do not contain significant amounts of refractory minerals enrich- ed in REE and Y, because the analytical results do not differ significantly between the two sample solutions after the dissolution by $\mathrm{HCl}$ alone and after the complete dissolution by flux of sodium carbonate plus boric acid. It seems difficult to judge whether the dolomitization and metamorphisms had altered the essential feature of the REE pattern or not. However, it is unlikely that refractory minerals enriched in REE were originally present but completely decomposed during the dolomitization and metamorphism. Therefore, a unique depositional environment, where quartz-rich detritus materials having no significant $\mathrm{Y}$ and REE stratificated 
together with calcareous materials, is suggested.

Although the types of limestones examined here are limited, it can be concluded that the REE and $\mathrm{Y}$ abundances in limestones provide us important information on the depositional environments of source materials of the respective limestones. Besides the usual discussions about $\mathrm{Ce}$ and $\mathrm{Eu}$ anomalies, the presence or absence of terrigenous materials in limestones can be shown by comparing the abundance patterns of REE plus $\mathrm{Y}$ for limestones with the unique pattern for the surface seawater characterized by the W-type tetrad effect and the non-chondritic $\mathrm{Y} / \mathrm{Ho}$ ratio.

\section{"Y Anomalies" in Seawaters and W-tvpe Tetrad Effect}

We emphasized that the REE and $\mathrm{Y}$ abundance patterns for the surface seawater and for the Permian limestone samples (EL-1 and EL-2) from Ohnogahara are commonly characterized by the W-type tetrad effect, the unusually high Y/Ho ratio greater than the chondritic value, and the negative anomalies of $\mathrm{Ce}$ and $\mathrm{Eu}$ (Fig. 1). However, we also emphasize here that they are not exactly the same. For example, the abundance patterns of the fourth tetrad for the two limestones can be shown by inclined smooth curves, but heavy REE of the fourth tetrad for the surface seawater displays a rather flat abundance pattern with a slight concavity. Our estimate of the $\mathrm{Y} / \mathrm{Ho}$ ratio for the surface seawater is about twice of the chondritic value but it is still smaller than the observed $\mathrm{Y} / \mathrm{Ho}$ ratios in the Ohnogahara limestones. In order to discuss these characteristics, we briefly refer to some physico-chemical processes controlling the abundances of REE and $\mathrm{Y}$ in seawaters.

The Nd isotopic compositions in seawaters and in oceanic hydrogenous sediments indicate that continental input is the major source of REE in seawaters (Palmer and Elderfield, 1985 and references therein). Major pathways of these elements from the continents to the oceans are the rivers. Recent studies on REE in estuarine waters and their suspensions suggests that significant fractions up to $70-80 \%$ of riverine REE fluxes are removed in estuarine areas of the river- ocean boundary (Elderfield et al., 1990). Particulate and colloidal forms of REE are thought to be removed considerably as the mixed colloids of $\mathrm{Fe}$ hydroxide and organic matter coagulate rapidly in an early stage of the estuarine mixing process (Hoyle et al., 1984; Elderfield et al., 1990). The remaining small fraction of particulate and colloidal REE together with dissolved REE are the continental supply to the oceans. However, the $\mathrm{Y}$ behavior in conjunction with REE cannot be inferred from the geochemical studies on estuarine mixing by Elderfield and coworkers, because they do not involve any $\mathrm{Y}$ data.

The results for the Gironde estuarine waters by Martin et al. (1976) seem important, because they present the analytical results of Y and REE for particulates and water solutions in the Gironde Estuary, France. They have filtered raw water samples using a $0.45 \mu \mathrm{m}$ Millipore filter and separated them into suspended particulates and solutions. Both the solution and suspension from a water sample with the minimum salinity of $S=0.1 \%$ show REE abundance patterns comparable with those of continental rocks having no $\mathrm{Y}$ anomaly. The REE plus $\mathrm{Y}$ patterns for suspensions from other estuarine water samples are almost the same as above irrespective of their salinities. However, the solutions separated from the waters with $\mathrm{S}=\mathbf{7 . 0}$ and $28.3 \%$ show Wtype REE patterns with positive $\mathrm{Y}$ anomalies (Fig. 3). These characteristics are definitely clear in the solution with the maximum salinity of 28.3\% . The results by Martin et al. (1976), therefore, are an important observation suggesting that fine particles of terrigenous materials in estuarine waters with higher salinities become more likely to be filtered. As a result, the contribution of unfiltered terrigenous solid particles to the $\mathrm{Y}$ and REE in filtrates becomes less important with increasing salinity, and then the intrinsic features of abundances patterns for dissolved Y and REE become visible.

This interpretation is consistent with the conclusion by Elderfield et al. (1990) as to the coagulation of particulates and colloids in the estuarine mixing process. Therefore, estuarine 


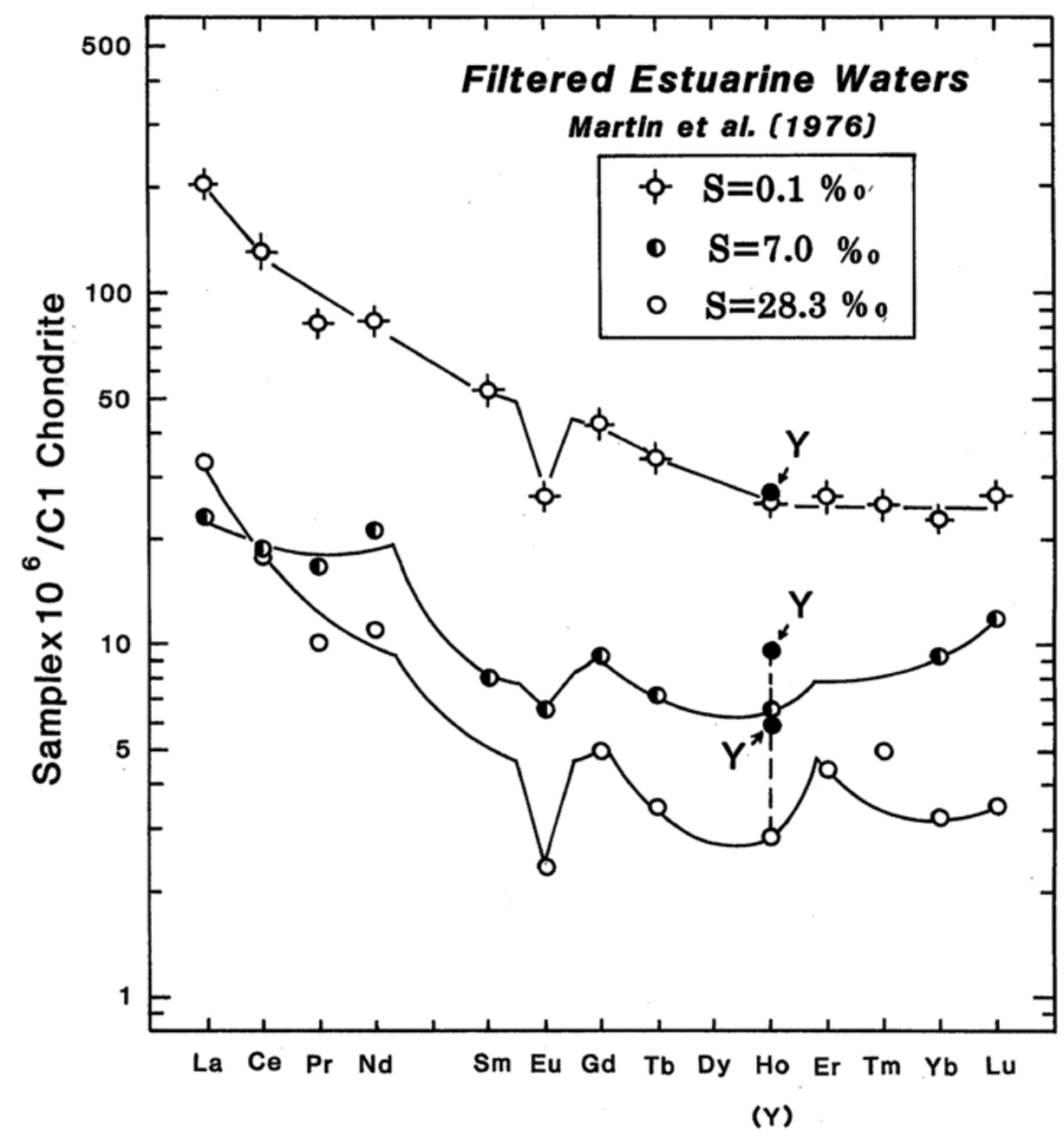

Fig. 3. The enrichment patterns of REE and $Y$ in the filtered Gironde estuarine waters reported by Martin et al. (1976).

waters as well as seawaters are to be understood as the natural environments in which terrigenous fine particles are effectively transformed into the particulates separable from the dissolved chemicals. Such particulates are likely to be separated from ambient solutions in the natural environments, and they are easily separable by artificial filtering procedure as well.

Figure 4 shows the REE plus Y abundance patterns of deep seawaters in the central Atlantic by Høgdahl et al. (1968). The recent NAA data of REE by De Baar et al. $(1983,1985 b)$ for deep seawaters in the western North Atlantic are also shown for comparison. A and B correspond to the averages for the seawaters at approximate depths of 1,000 and $4,500 \mathrm{~m}$, respectively. The data sets by De Baar et al. $(1983,1985 b)$ are multiplied by respective constant factors of 0.71 for $\mathrm{A}$ and $\mathbf{0 . 5 6}$ for $\mathrm{B}$ in order to make the relative abundances of $\mathrm{Sm}$ in the two sets to be common. Both the relative REE patterns for the Atlantic deep seawaters by Høgdahl et al. (1968) and by De Baar et al. (1983, 1985b) are very similar despite their diffrences in sample locations and pre-concentration methods for analyses. We believe that the reliability of REE 


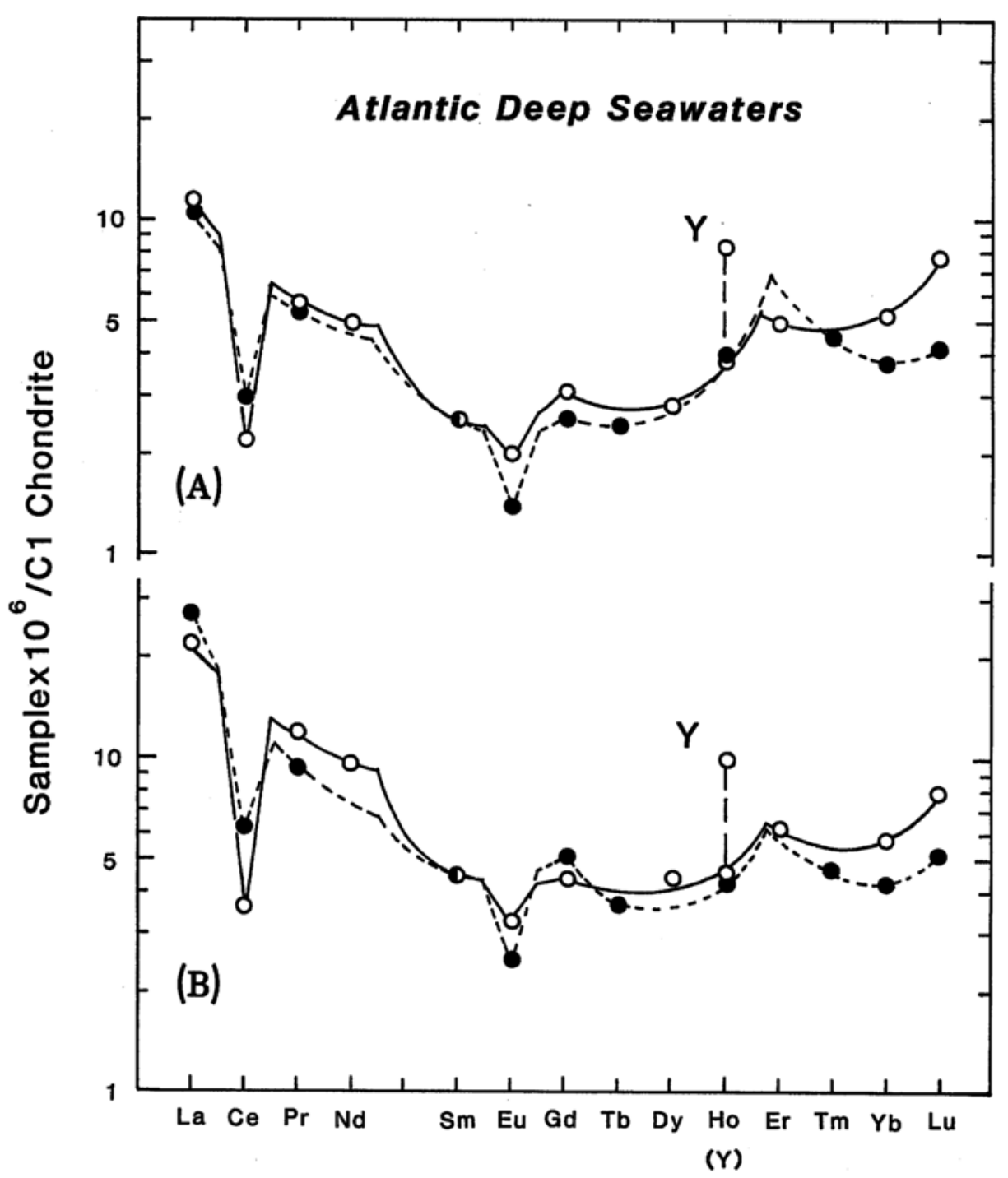

Fig. 4. REE and Y abundance patterns for deep sea waters at approximate depths of 1,000 $m(A)$ and of 4,500 $m(B)$ in the Atlantic. Open circles: Average values of NAA data for seawaters in the Central Atlantic by Høgdahl et al. (1968). Solid circles: NAA data for sea water samples from the western North Atlantic Ocean by De Baar et al. (1983 and 1985b). In order to make the Sm abundances to be common between two sets of data, all the REE values for the deep seawaters from the western North Atlantic are multiplied in A and B by the constant factors of 0.71 and 0.56 , respectively.

and Y data reported by Høgdahl et al. (1968) is endorsed by the recent data. Their $\mathrm{Tb}$ and $\mathrm{Tm}$ values, however, seem to be subjected to large analytical errors as suggested by large apparent variations in the original data. So that we do not show the $\mathrm{Tb}$ and $\mathrm{Tm}$ data points by Høgdahl et al. (1968).

The analytical results by Høgdahl et al. (1968) have been obtained for the unfiltered water samples, suggesting that any particulates in their water samples, if present, must have been analyzed together with dissolved $\mathrm{Y}$ and 
REE. In De Baar et al. (1983 and 1985b), on the other hand, sampled waters were pumped through a Chelex-100 column. Particulates must have been removed in the chromatographic column. The reasonable agreement between the REE patterns based on the analyses with and without associated particulates suggests that the presence of REE and probably $\mathrm{Y}$ in particulateforms are insignificant in thier samples of the Atlantic deep seawaters. Therefore, it is concluded that dissolved Y and REE in deep seawaters display the abundance patterns characterized by the positive $\mathrm{Y}$ anomalies and $\mathrm{W}$-type tetrad effect just like those in the surface seawaters.

\section{"Y-anomalies" in Limestones and Marine Deposits}

From the discussion about $\mathrm{Y}$ and REE data on estuarine waters and seawaters as above, we can infer that natural waters having no terrigenous nor authigenic particulates show the REE plus $\mathrm{Y}$ abundance patterns having the $\mathrm{W}$ type tetrad effect and positive $\mathrm{Y}$ anomaly. This inference is partly justified by the observations that W-type REE patterns are seen in fresh groundwaters and valves of fresh water shellfish (Masuda et al., 1987).

We understand that the positive $\mathrm{Y}$ anomaly and $\mathrm{W}$ type tetrad effect are originated from thermodynamic processes related to the solubilities of $\mathrm{Y}$ and REE in reactive phases like hydroxides involving $\mathrm{Fe}$ and $\mathrm{Mn}$. The systematic differences in $4 \mathrm{f}$ electronic configurations across the trivalent REE series and the absence of $4 \mathrm{f} \mathrm{elec-}$ tron in $\mathrm{Y}$ can be reflected upon the thermodynamic process in the natural aqauatic environments. If $\mathrm{Y}$ is a pseudo lanthanide which always behaves like Ho, the intimate association of the $\mathrm{Y}$ anomaly with W-type tertad effect in seawaters cannot be explained. The reason why the hydrogeneous deposits of deep-sea ferromanganese nodules display the REE patterns basically similar to those of the terrigenous materials of shales is also explainable from this viewpoint: The deep-sea ferromanganese nodules are formed as the precipitates from seawater solutions partly influenced by pore waters from the seawater/sediment interface, and the precipitation is just a reverse process of the dissolution.

Keeping these points in mind, we have compared the variations of $\mathrm{Y} / \mathrm{Ho}, \mathrm{Y} / \mathrm{Yb}$ and $\mathrm{Yb} / \mathrm{Ho}$ ratios in seawaters and marine deposits including the limestones in this study (Fig. 5). The plotted data points are not many, because reliable data sets including REE and Y together are limited even today. Furthermore, because of the lower abundance of $\mathrm{Ho}$ in the nature, the analytical uncertainty for Ho must be larger than those for $\mathrm{Yb}$ and $\mathrm{Y}$, whatever is the analytical method. Despite these difficulties, we can see the following points in Fig. 5: (1) Besides the three limestones shown in Fig. 1, the marine phosphorites as well as seawaters indicate large $\mathrm{Y} / \mathrm{Ho}$ and $\mathrm{Y} / \mathrm{Yb}$ ratios twice as great as the respective chondritic ratios, (2) The Red Creek marble shown in Fig. 2 and the argillaceous limestones by Jarvis, I. and Jarvis, K. E. (1985) are plotted close to the shale (NASC), but their $\mathrm{Y} / \mathrm{Ho}$ and $\mathrm{Y} / \mathrm{Yb}$ ratios are slightly higher the chondritic ratios, (3) The deep-sea ferromanganese nodules analyzed in our laboratory and the marine sediments including one estuarine sediment reported by Jarvis, I. and Jarvis, K. E. (1985) show the $\mathrm{Y} / \mathrm{Ho}$ and $\mathrm{Y} / \mathrm{Yb}$ ratios slightly smaller than NASC, and (4) The deviations of data points for the marine deposits from the chondrite or NASC in Fig. 5 appear to be consistent with the observed variation of $\mathrm{Yb} / \mathrm{Ho}$ ratios in seawaters by De Baar et al. (1983, 1985a, b).

We like to emphasize that the marine phosphorites show positive $\mathrm{Y}$ anomalies but the ferromanganese nodules and marine sediments tend to show negative $\mathrm{Y}$ anomalies. Masuda and Ikeuchi (1979) have pointed out that the REE abundance pattern for the marine phosphorite reported by Goldberg et al. (1964) exhibits a well defined tetrad effect of the $\mathrm{W}$ type just like seawaters. This is also the case for the phosphorites plotted in Fig. 5. The marine sediments and the deep-sea ferromanganese nodules shown in Fig. 5 display the REE patterns analogous to those of terrigenous materials like shales. Even though both of the phosphorite 


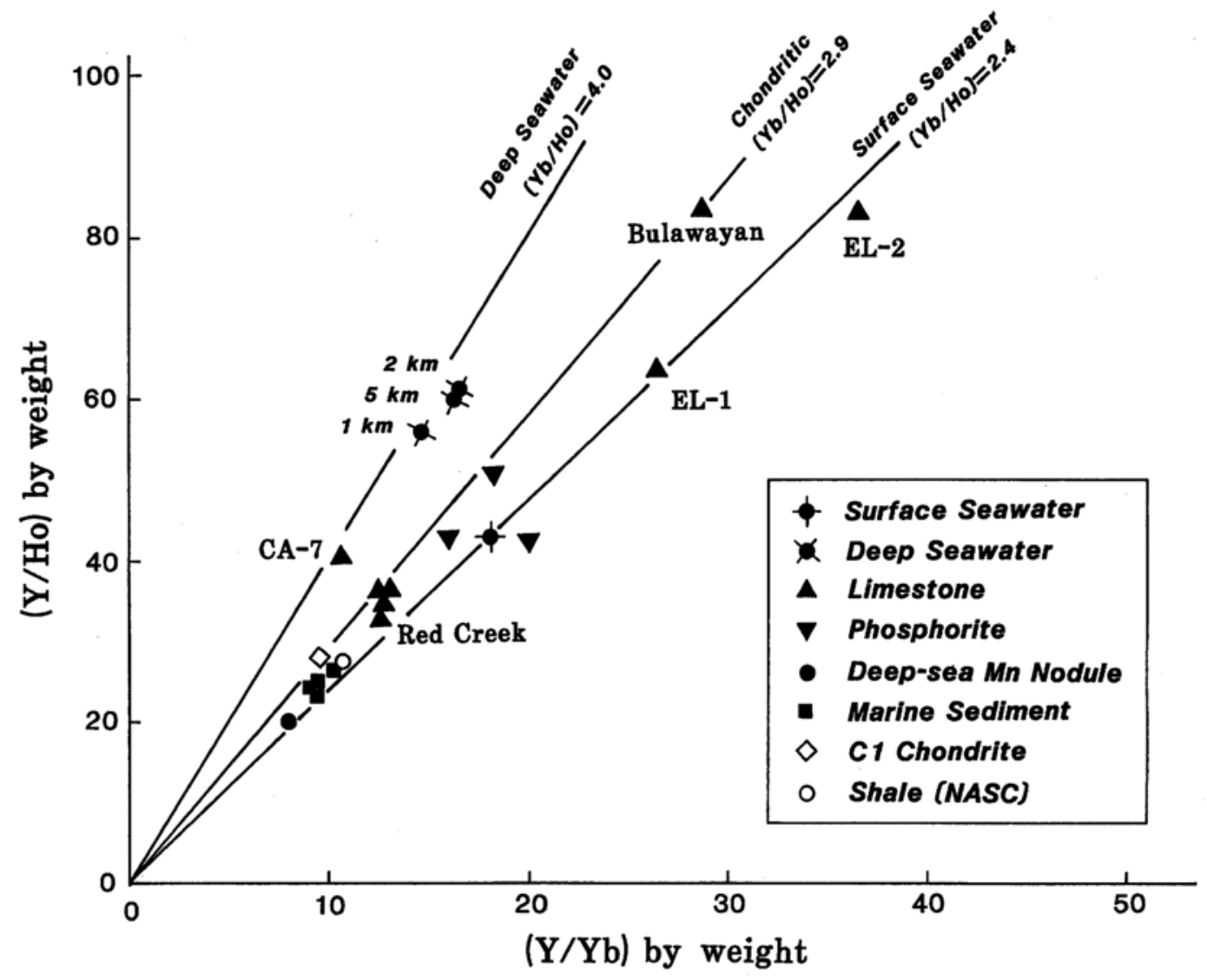

Fig. 5. Plots of $\mathrm{Y} / \mathrm{Ho}$ ratio against $\mathrm{Y} / \mathrm{Yb}$ for limestones, marine deposits and seawaters in reference to $\mathrm{Cl}$ chondrite and NASC shale. Sources for the data points other than those in Table 1 and Figs. 1 and 2 of this study are as follows: NASC shale (Gromet et al., 1984; Haskin et al. 1966), Deep seawaters (Averages for three different approximate depths as indicated, based on the NAA data by Hogdahl et al., 1968), Limestones (two argillaceous limestones and a dolomitic limestone by Jarvis, I. and Jarvis, K. E., 1985), Phosphorites (Haskin et al., 1966; Jarvis, I. and Jarvis, K. E., 1985), Deep-sea Mn nodule (Average of eleven ferromanganese nodules from the central Pacific, unpublished data in our laboratory), and Marine sediments (two marine sediments, one estuarine sediment, and one marine mud by Jarvis, I. and Jarvis, K. E., 1985). The Yb/Ho ratios for shallow and deep seawaters are based on the results for the VERTEX II site in the Pacific (De Baar et al., 1985a).

and the ferromanganese nodule are marine authigenic deposits, they have contrasting characteristics of REE plus $\mathrm{Y}$ abundance patterns. Therefore, the intimate association of the nonchondritic $\mathrm{Y} / \mathrm{Ho}$ ratios with the W-type lanthanide tetrad effect in limestones and seawaters reported in this paper is merely one clue to reconsider the dissolution and precipitation reactions involving seawaters and various authigenic phases from the thermodynamic behaviors of REE and Y. The observed variety of Y/Ho frac- tionations in Fig. 5 and the tetrad effects in seawaters and limestones shown here may also suggest that such rate processes of scavenging and regeneration of REE and $\mathrm{Y}$ in seawater columns are important in addition to the admixing process of terrigenous and marine authogenic materials. These processes in natural aquatic environments, anyhow, make it visible that $\mathrm{Y}$ is not a pseudo lanthanide behaving like Ho. 
Acknowledgments-We are grateful to Dr. M. Komatsu (Ehime University) for his discussion and suggestions as to the Hida calc-silicate gneiss. Mr. M. Sudo in our laboratory helped us in field and analytical works. We also thank Dr. T. Masuzawa (Water Research Institute, Nagoya University) for his helpful advice on literature data of seawater chemistry. This work was supported in part by a grant from Ehime University and by a grant for DELP from the Ministry of Education, Science and Culture, Japan.

\section{REFERENCES}

Anders, E. and Grevesse, N. (1989) Abundances of the elements: Meteoritic and solar. Geochim. Cosmochim. Acta 53, 197-214.

Daidoji, M., Tamura, S. and Matsubara, M. (1985) Determination of rare earth elements and thorium in sea water by inductively coupled plasma atomic emission spectrometry. Bunseki Kagaku 34, 340345.

De Baar, H. J. W., Bacon, M. P. and Brewer, P. G. (1983) Rare-earth distributions with a positive Ce anomaly in the western North Atlantic Ocean. Nature 301, 324-327.

De Baar, H. J. W., Bacon, M. P., Brewer, P. G. and Bruland, K. W. (1985a) Rare earth elements in the Pacific and Atlantic oceans. Geochim. Cosmochim. Acta 49, 1943-1959.

De Baar, H. J. W., Brewer, P. G. and Bacon. M. P. (1985b) Anomalies in rare earth distributions in seawater: Gd and Tb. Geochim. Cosmochim. Acta 49, 1961-1969.

Elderfield, H., Upstill-Goddard, R. and Sholkovitz, E. R. (1990) The rare earth elements in rivers, estuaries, and coastal seas and their significance to the composition of ocean waters. Geochim. Cosmochim. Acta 54, 971-991.

Goldberg, E. D., Koide, M., Schmitt, R. A. and Smith, R. H. (1963) Rare earth distribution in the marine environment. J. Geophys. Res. 68, 42094217.

Gromet, L. P., Dymek, R. F., Haskin, L. A. and Korotev, R. L. (1984) The "North American Shale Composite": Its compilation, major and trace element characteristics. Geochim. Cosmochim. Acta 48, 2469-2482.

Haskin, L. A., Frey, F. A., Schmitt, R. A, and Smith, R. H. (1966) Meteoric, solar and terrestrial rareearth distributions. Phys. Chem. Earth 7, 167-321.

Haskin, L. A., Wildeman, T. R., Frey, F. A., Collins, K. A., Keedy, C. R. and Haskin, M. A. (1966) Rare earths in sediments. J. Geophys. Res. 71, 60916105.
Høgdahl, O. T., Welsom, S. and Bowen, V. T. (1968) Neutron activation analysis of lanthanide elements in sea water. Adv. Chem. Ser. 73, 308-325.

Hoyle, J., Elderfield, H., Gledhill, A. and Greaves, M. (1984) The behaviour of the rare earth elements during mixing of river and sea waters. Geochim. Cosmochim. Acta 48, 143-149.

Jarvis, I. and Jarvis, K. E. (1985) Rare-earth element geochemistry of standard sediments: a study using inductively coupled plasma spectrometry. Chem. Geol. 53, 335-344.

Jørgensen, C. K. (1970) The "tetrad effect" of Peppard is a variation of the nephelauxetic ratio in the third decimal. J. Inorg. Nucl. Chem. 32, 31273128.

Kamioka, H. and Masuda, A. (1986) Rare earth elements in Precambrian limestones. 1986 Ann. Meeting Geochem. Soc. Japan Abstr. 33.

Kanmera, K. (1987) Carbonate rocks. Sedimentary Rocks in Japan, Mizutani, S., Saito, T. and Kanmera, K. eds., pp. 85-142, Iwanami Shoten, Tokyo.

Kawabe, I., Okumura, M. and Ochi, M. (1988) Chemical analysis of silicate glass and rock samples by inductyively coupled argon plasma atomic emission spectrometry. Mem. Ehime Univ. Sci. Ser. D. 11, 1-13.

Martin, J.-M., Hogdahl, O. and Philippot, J. C. (1976) Rare earth element supply to the ocean. $J$. Geophys. Res. 81, 3119-3124.

Masuda, A. (1975) Abundances of monoisotopic REE, consistent with the Leedey chondrite values. Geochem. J. 9, 183-184.

Masuda, A., Nakamura, N. and Tanaka, T. (1973) Fine structures of mutually normalized rare-earth patterns of chondrites. Geochim. Cosmochim. Acta 37, 239-248.

Masuda, A. and Ikeuchi, Y. (1979) Lanthanide tetrad effect observed in marine environment. Geochem. J. 13, 19-22.

Masuda, A., Kawakami, O., Dohmoto, Y. and Takenaka, T. (1987) Lanthanide tetrad effects in nature: two mutually opposite types, $\mathrm{W}$ and $\mathrm{M}$. Geochem. J. 21, 119-124.

Masuda, A. and Akagi, T. (1989) Lanthanide tetrad effect observed in leucogranites from China. Geochem. J. 23, 245-254.

Nugent, L. J. (1970) Theory of the tetrad effect in the lanthanide (III) and actinide (III) series. J. Inorg. Nucl. Chem. 32, 3485-3491.

Palmer, M. R. and Elderfield, H. (1985) Variations in the $\mathrm{Nd}$ isotopic composition of foraminifera from Atlantic ocean sediments. Earth Planet. Sci. Lett. 73, 299-305.

Peppard, D. F., Mason, G. W. and Lewey, S. (1969) 
A tetrad effect in the liquid-liquid extraction ordering of lanthanides (III). J. Inorg. Nucl. Chem. 31, 2271-2272.

Peppard, D. F., Bloomquist, C. A. A., Horwitz, E. P., Lewey, S. and Mason, G. W. (1970) Analogous actinide (III) and lanthanide (III) tetrad effects. $J$. Inorg. Nucl. Chem. 32, 343-344.

Wildeman, T. R. and Haskin, L. A. (1973) Rare earths in Precambrian sediments. Geochim. Cosmochim. Acta 37, 419-438. 